\title{
Formulation and in vitro evaluation of superporous hydrogel based gastroretentive drug delivery system of vildagliptin
}

\author{
Prasanna Kumar DESU 1 * (D), Venkateswararao PASAM 2 (D) , Vijay KOTRA 3 (D) \\ 1 Department of Pharmaceutics, Vishnu Institute of Pharmaceutical Education and Research, Narsapur, Medak (Dt), \\ Telangana - 502313. \\ 2 Department of Pharmaceutical Chemistry, St. Mary's Group of Institutions Guntur, Chebrolu (V\&M), Guntur, \\ Andhra Pradesh, India - 522212. \\ 3 Department of Pharmaceutical Chemistry, Faculty of Pharmacy, Quest International University Perak, 30250 Ipoh, \\ Malaysia. \\ * Corresponding Author. E-mail: prasanna.desu@gmail.com (P.K.D.); Tel. +99-669-163 29.
}

Received: 22 May 2019 / Revised: 06 July 2019 / Accepted: 17 July 2019

\begin{abstract}
Numerous medications, which have a tight restorative window and are consumed predominantly in the stomach have been created as a gastroretentive conveyance framework. Vildagliptin, an antidiabetic, is exceedingly temperamental at fundamental $\mathrm{pH}$ and is widely retained from the stomach. Henceforth there is a need to build up a gastroretentive framework. In this investigation a superporous hydrogel was created as a gastroretentive medication conveyance framework. Superporous hydrogels were readied utilizing a gas forming method utilizing N', N'- BIS as the crosslinking operator and polyvinyl Alcohol as a composite specialist. Swelling practices of the superporous hydrogel in acidic arrangement were concentrated to explore their applications for gastric maintenance gadget. The ideal arrangement state of superporous hydrogels was gotten from the swelling and in vitro medication discharge thinks about. FT-IR, SEM and DSC contemplates were utilized to portray the similarity between polymers. As the grouping of crosslinker expanded from 0.5 to $3 \%$ the porosities diminished. In reenacted gastric liquid superporous hydrogels demonstrated a decent increment in harmony swelling limit. Checking electron infinitesimal pictures plainly showed the arrangement of interconnected pore and slim channels. Portrayal thinks about uncovered that the expansion in crosslinker focus is beneficial from the swelling proportion, and yet the decline in porosity may prompt abatement in medication discharge rate by dispersion through these narrow channels. The medication discharge from superporous hydrogels appeared for a drawn out timeframe. Structure the discharge energy it uncovered that sedate pursues the Non - Fickian mechanism. FTIR and DSC ponders uncovered that there were no critical collaborations between the drug and polymers. In light of the portrayal thinks about, it was uncovered that superporous hydrogels could be utilized as a gastroretentive medication conveyance framework for vildagliptin in perspective on their swelling and delayed medication discharge qualities in acidic $\mathrm{pH}$.
\end{abstract}

KEYWORDS: Vildagliptin; superporous hydrogel; crosslinking agent; polyvinyl alcohol; swelling ratio.

\section{INTRODUCTION}

In the present time focusing of the medication at a specific site has turned into a significant piece of pharmaceutical research. Be that as it may, different issues are watched while focusing of medication atom at explicit destinations, for example, quick end, debasement and short living arrangement time. In the course of the most recent couple of decades, the engaged has been made in structuring of gadget that can hold in the upper piece of the gastrointestinal tract (GIT) as far as improving medication home time of medication at focusing on locales. There are different advancements have been utilized for a gastroretentive gadget, for example, low-density systems [1], high-density systems [2], bioadhesive systems[3] and expanding systems[4]. However, these frameworks are influenced by different factors, for example, gastric liquid substance, brutal gastric condition, gastric constriction and nourishment content. These components bring about lessening gastric maintenance time. Superporous hydrogels based GRDDS have been structured by numerous scientists as a gastric maintenance gadget. They have the attributes to retain a lot of water and swell due to having a hydrophilic practical gathering in their structure. This swelling property is dependable to keep the detailing

How to cite this article: Desu PK, Pasam VR, Kotra V. Formulation and in vitro evaluation of superporous hydrogel based gastroretentive drug delivery systems of vildagliptin. J Res Pharm. 2019; 23(5): 873-885. 
in the stomach for a drawn out timeframe. Therefore based on great swelling and mechanical properties permeable hydrogel were readied. These have versatile property because of the joining of a composite specialist like polyvinyl liquor. They can withstand for a significant timeframe [5].

Type 2 diabetes mellitus is a developing issue in many pieces of the world. There is currently great proof that controlling hyperglycaemia can help avert huge numbers of the genuine entanglements related with the sickness [6]. Ebb and flow drugs utilized for overseeing TYPE II Diabetes and its antecedent disorders, for example, insulin obstruction, fall into various classes of a compound, for example, the biguanides, thiazolidinediones, the sulfonylureas peptide undifferentiated from, dipeptidyl Peptidase-IV inhibitors and alpha-glucosidase inhibitors [7]. Among the most encouraging new classes of medications for sort 2 diabetes are those that influence the incretin hormone glucagon-like peptide-1 (GLP-1). Vildagliptin is an oral antidiabetic sedate from the peptide analogs (DPP4 inhibitor class). Vildagliptin can be given in monotherapy just as in blend with other antidiabetic drugs. It quickly and totally restrains the movement of DPP-4 catalysts this outcomes in an expansion of the two incretin hormones accessible in our body, they are glucose-like peptide1 (GLP-1) and glucose-subordinate insulinotropic peptide (GIP). The enactment of these two hormones results in a reduction of the blood glucose level by diminishing the glucagon emission and an expansion of insulin affectability. GLP-1 actuation upgrades the $\beta$-cell affectability and lessens the $\alpha$-cell affectability, which results in an expansion in the measure of insulin and diminishes the measure of glucagon and decreases the glucose level in blood [8].

Controlled-discharge oral conveyance frameworks are intended to accomplish remedially successful convergences of medication in the fundamental course over an all-encompassing timeframe, in this manner accomplishing better patient consistence and permitting a decrease of both the absolute portion of medication regulated and the frequency of antagonistic reactions [9]. In long haul treatment, for the treatment of perpetual ailment conditions, customary details are required to be managed in numerous dosages and in this way have a few detriments.

The primary target of the present research work was planned vildagliptin stacked superporous hydrogels for gastric maintenance in the treatment of sort II diabetes. Vildagliptin is an oral enemy of hyperglycemic specialist of the dipeptidyl peptidase-4 (DPP-4) inhibitor class of medications. Vildagliptin restrains the inactivation of GLP-1[[10,11] and GIP[11] by DPP-4, permitting GLP-1 and GIP to potentiate the emission of insulin in the beta cells and smother glucagon discharge by the alpha cells of the islets of Langerhans in the pancreas. After oral organization, crest plasma focus accomplished inside a brief timeframe. Its organic half-life is $90 \mathrm{mins}$. Vildagliptin is steady in acidic media however experiences debasement in basic medium.

\section{RESULTS AND DISCUSSIONS}

In this investigation superporous hydrogels were blended by gas blowing strategy utilizing acrylic acid and acrylamide as a monomers, $\mathrm{N}, \mathrm{N}^{\prime}$ - methylene Bisacrylamide as a crosslinker, ammonium persulfate and $\mathrm{N}, \mathrm{N}, \mathrm{N}, \mathrm{N}$-tetra methylene diamine as an initiator pair, Polyvinyl Alcohol as a composite agent and Span 80 as a surfactant go about as a froth stabilizer to make permeable structure.

\subsection{Apparent density, porosity and void fraction}

The apparent densities, porosity and a Void portion of the superporous hydrogels extended between $0.55 \pm 0.09$ and $0.79 \pm 0.07 \mathrm{~g} / \mathrm{cm}^{3}, 49.51 \pm 0.77$ to $77.65 \pm 0.53$ and $1.27 \pm 0.01$ to $1.58 \pm 0.03$ individually and values were spoken to in Table 1 and graphically appeared in Figure 1 to 3 . Since the hydrogels are extremely permeable, the deliberate thickness is identified with the porosity of the polymer and can be characterized as evident thickness. The real thickness of the polymer is the equivalent yet when the polymer has less pores, the involved volume will be less, in this way bringing about high obvious thickness. Along these lines, it was seen that with addition in BIS fixation there was additionally expanding in evident thickness of superporous hydrogels. From Table 1 it was seen that with expanding BIS focuses there become all the more solid structure around the void space because of denser system arrangement between interpolymeric systems and henceforth less space accessible for pore development. With expanding BIS focus, thickness detailing expanded that aggregated at polymeric space and in this way builds void space. 
Table 1. Characterization of SPH Formulations.

\begin{tabular}{ccccc}
\hline $\begin{array}{c}\text { Formulation } \\
\text { Code }\end{array}$ & $\begin{array}{c}\text { Density }\left(\mathbf{g} / \mathbf{c m}^{3}\right) \\
*\end{array}$ & Porosity $(\%)^{*}$ & Void Fraction $(\mathbf{m l} / \mathbf{g})^{*}$ & Drug Content $^{*}$ \\
\hline F1 & $0.59 \pm 0.15$ & $61.26 \pm 0.39$ & $1.29 \pm 0.02$ & $97.62 \pm 0.99$ \\
F2 & $0.67 \pm 0.14$ & $55.77 \pm 0.51$ & $1.27 \pm 0.01$ & $98.27 \pm 0.54$ \\
F3 & $0.54 \pm 0.03$ & $77.65 \pm 0.53$ & $1.58 \pm 0.03$ & $98.89 \pm 0.86$ \\
F4 & $0.63 \pm 0.08$ & $73.76 \pm 0.25$ & $1.52 \pm 0.02$ & $97.49 \pm 1.07$ \\
F5 & $0.60 \pm 0.04$ & $54.08 \pm 0.39$ & $1.27 \pm 0.01$ & $96.78 \pm 1.77$ \\
F6 & $0.79 \pm 0.07$ & $49.51 \pm 0.77$ & $1.24 \pm 0.04$ & $98.5 \pm 0.64$ \\
F7 & $0.55 \pm 0.09$ & $70.47 \pm 0.25$ & $1.46 \pm 0.05$ & $98.32 \pm 1.01$ \\
F8 & $0.58 \pm 0.04$ & $64.72 \pm 0.89$ & $1.38 \pm 0.01$ & $99.28 \pm 0.52$ \\
\hline
\end{tabular}

${ }^{*}$ Mean \pm SD, $\mathrm{n}=3$.

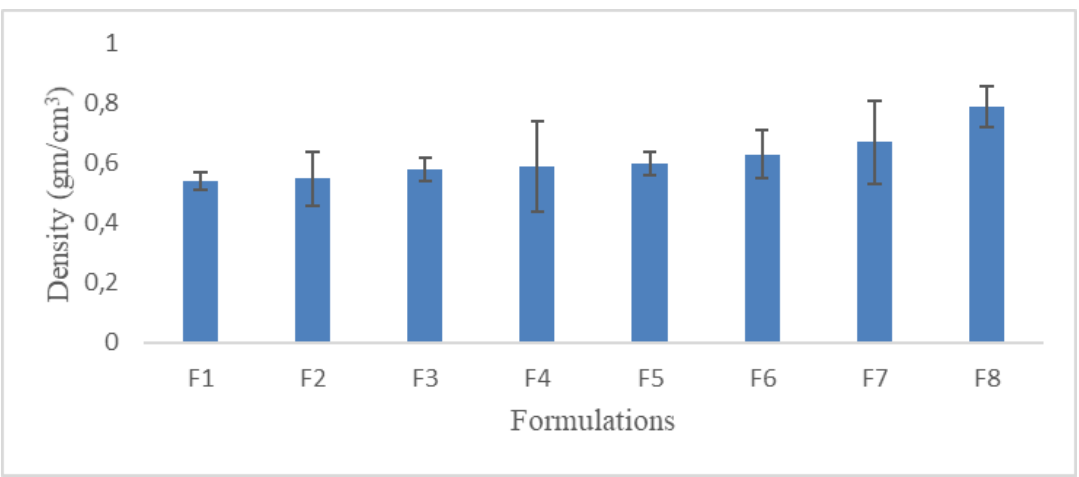

Figure 1. Density profile of vildagliptin loaded SPH Formulations.

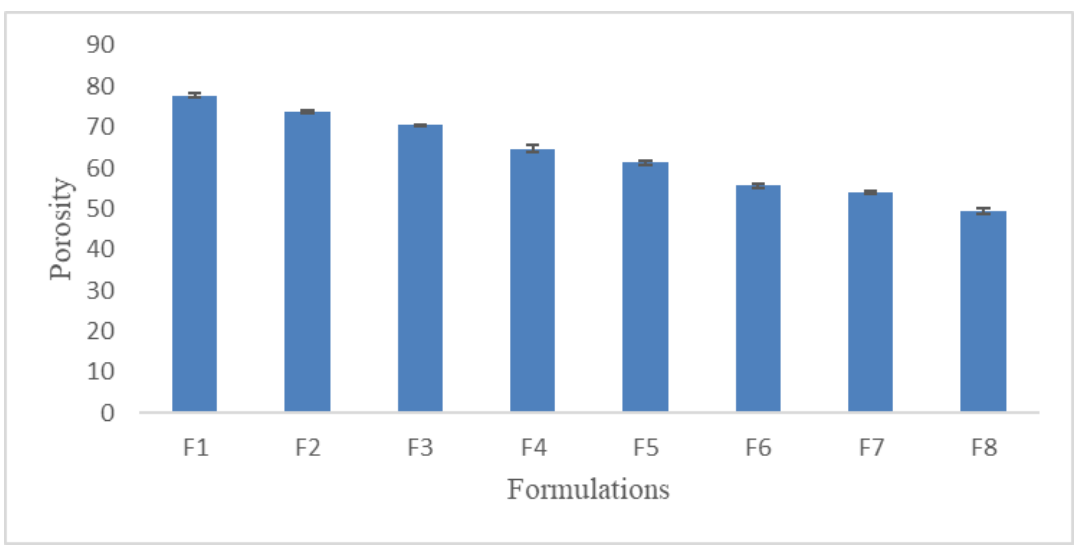

Figure 2. Porosity profile of vildagliptin loaded SPH Formulations.

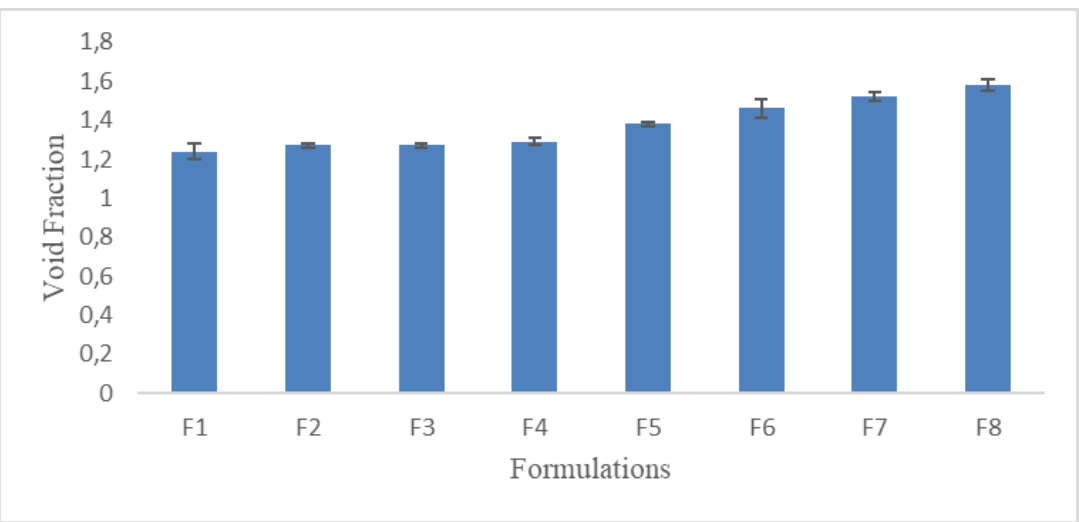

Figure 3. Void fraction profile of vildagliptin loaded SPH Formulations. 


\subsection{Swelling ratio}

The swelling ratio of all detailing in the recreated gastric liquid was appeared Table 2 and 3 and graphically spoke to in Figure 4. It was seen from results that the swelling proportion of superporous hydrogel was influenced with shifting centralization of BIS. It was discovered that swelling proportion was expanded with expanding the BIS focus from 1.0 to $3.0 \% \mathrm{w} / \mathrm{v}$.

Table 2. Swelling Ratio of formulations F1 to F4.

\begin{tabular}{ccccc}
\hline Time in mins & F1 & F2 & F3 & F4 \\
\hline 0 & 0 & 0 & 0 & 0 \\
10 & $22.83 \pm 1.53$ & $19.17 \pm 1.53$ & $17.67 \pm 1.76$ & $24.08 \pm 1.51$ \\
20 & $46.00 \pm 1.50$ & $41.02 \pm 2.14$ & $30.50 \pm 1.32$ & $31.40 \pm 1.71$ \\
30 & $62.67 \pm 1.76$ & $55.90 \pm 2.51$ & $41.83 \pm 1.53$ & $47.22 \pm 1.60$ \\
60 & $76.50 \pm 1.80$ & $73.41 \pm 2.55$ & $55.67 \pm 1.26$ & $65.18 \pm 1.52$ \\
120 & $89.50 \pm 2.29$ & $82.41 \pm 2.45$ & $75.83 \pm 1.26$ & $87.68 \pm 2.86$ \\
180 & $108.50 \pm 2.29$ & $89.65 \pm 1.88$ & $97.50 \pm 1.80$ & $102.94 \pm 2.55$ \\
240 & $125.00 \pm 1.00$ & $102.44 \pm 1.69$ & $116.33 \pm 1.26$ & $129.65 \pm 1.87$ \\
300 & $139.67 \pm 1.26$ & $119.53 \pm 1.45$ & $126.50 \pm 1.80$ & $147.62 \pm 2.38$ \\
360 & $151.17 \pm 0.76$ & $131.75 \pm 2.71$ & $137.00 \pm 1.50$ & $155.11 \pm 2.76$ \\
420 & $157.50 \pm 2.00$ & $146.67 \pm 2.48$ & $154.00 \pm 1.80$ & $165.65 \pm 1.80$ \\
480 & $167.33 \pm 1.61$ & $165.04 \pm 2.25$ & $175.00 \pm 1.32$ & $172.08 \pm 3.68$ \\
540 & $167.50 \pm 1.32$ & $166.33 \pm 2.36$ & $175.17 \pm 1.04$ & $172.40 \pm 3.58$ \\
\hline * Mean $\pm \mathrm{SD}, \mathrm{n}=3$ & & & &
\end{tabular}

Table 3. Swelling Ratio of formulations F5 to F6.

\begin{tabular}{ccccc}
\hline Time in mins & F5 & F6 & F7 & F8 \\
\hline 0 & 0 & 0 & 0 & 0 \\
10 & $25.50 \pm 1.50$ & $17.50 \pm 1.50$ & $23.00 \pm 1.0$ & $17.86 \pm 1.12$ \\
20 & $33.67 \pm 2.25$ & $32.83 \pm 1.61$ & $46.50 \pm 2.00$ & $28.92 \pm 1.14$ \\
30 & $47.00 \pm 1.32$ & $44.17 \pm 1.04$ & $60.67 \pm 1.76$ & $37.12 \pm 2.74$ \\
60 & $62.33 \pm 1.26$ & $57.33 \pm 2.02$ & $82.50 \pm 2.00$ & $55.36 \pm 1.51$ \\
120 & $85.83 \pm 1.53$ & $64.00 \pm 1.32$ & $98.67 \pm 1.76$ & $75.83 \pm 1.03$ \\
180 & $102.17 \pm 2.08$ & $76.17 \pm 1.76$ & $119.67 \pm 1.04$ & $95.18 \pm 2.98$ \\
240 & $112.83 \pm 1.26$ & $95.00 \pm 1.50$ & $130.00 \pm 1.32$ & $109.74 \pm 2.74$ \\
300 & $126.00 \pm 2.50$ & $109.33 \pm 1.76$ & $135.17 \pm 1.26$ & $122.46 \pm 1.14$ \\
360 & $135.00 \pm 0.87$ & $127.83 \pm 1.76$ & $143.33 \pm 2.02$ & $136.28 \pm 1.78$ \\
420 & $156.83 \pm 1.26$ & $143.50 \pm 2.00$ & $155.33 \pm 2.02$ & $153.98 \pm 1.54$ \\
480 & $163.00 \pm 1.80$ & $160.33 \pm 1.76$ & $170.83 \pm 1.04$ & $168.05 \pm 1.83$ \\
540 & $163.17 \pm 1.53$ & $160.50 \pm 2.0$ & $171.33 \pm 1.04$ & $168.70 \pm 1.54$ \\
\hline$*$
\end{tabular}

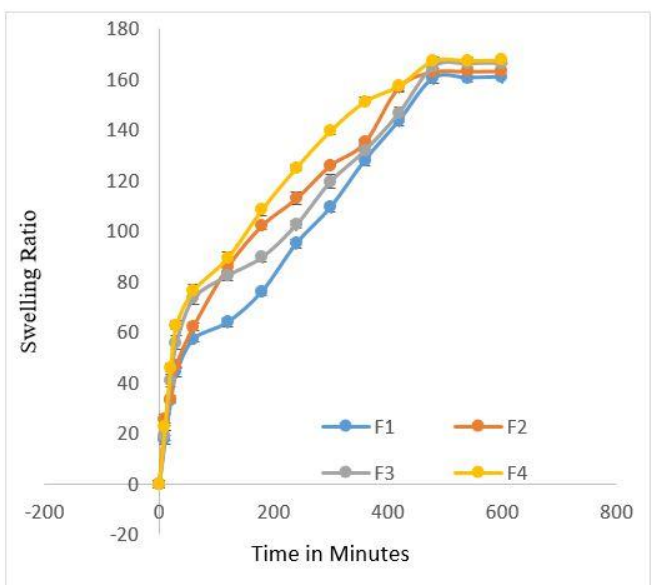

(A)

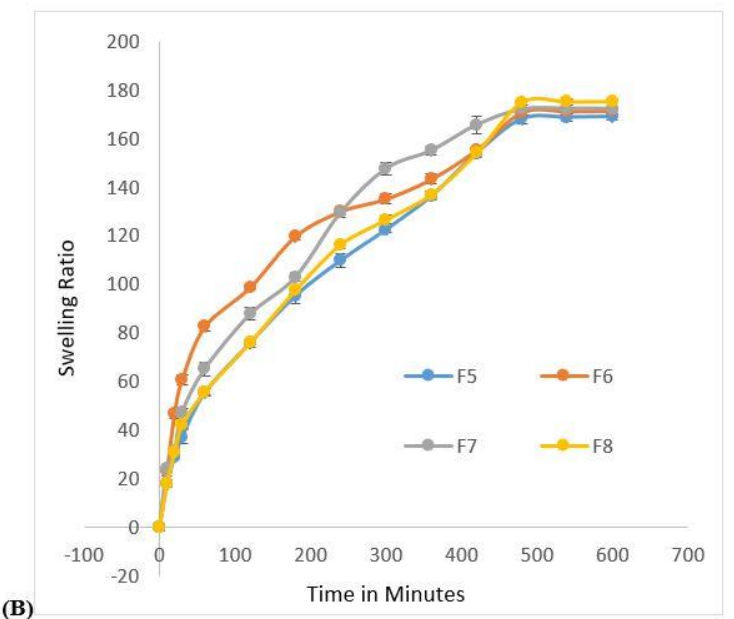

Figure 4. Swelling Ratio of formulations (A)F1 to F4 (B) F5 to F8. 


\subsection{Swelling reversibility studies}

The swelling reversibility investigations of improved detailing F7 in pH 1.2 and $\mathrm{pH} 7.4$ cradle were done for a time of 240 mins to watch the impact of swelling and deswelling capacities and the got outcomes were spoken to in the table and delineated graphically in the figure. The outcomes demonstrate the detailing F7 had the option to rapidly swell and deswell contingent upon the $\mathrm{pH}$ change from acidic conditions to essential conditions and the other way around. The ideal opportunity for swelling was longer than the deswelling of the hydrogels. This could be because of the confined chain portability of the hydrogels which was moored at a few through atomic entrapment with the IPA arrange, in light of the fact that the quick $\mathrm{pH}$ touchy conduct of hydrogels depended on the uninhibitedly versatile side chains. Indeed, even after many swelling and deswelling cycles, superporous hydrogel stayed unblemished demonstrating its basic respectability notwithstanding changes in $\mathrm{pH}$ of the outside condition. The results were shown in Table 4 and graphically represented in Figure 5.

Table 4. Swelling Reversibility data of Optimized Formulation F7.

\begin{tabular}{ccccccccc}
\hline $\mathbf{p H}$ & $\begin{array}{c}\text { Time } \\
\text { (mins) }\end{array}$ & $\begin{array}{c}\text { Swelling } \\
\text { Ratio* }^{*}\end{array}$ & $\begin{array}{c}\text { Time } \\
\text { (mins) }\end{array}$ & $\begin{array}{c}\text { Swelling } \\
\text { Ratio* }^{*}\end{array}$ & $\begin{array}{c}\text { Time } \\
\text { (mins) }\end{array}$ & $\begin{array}{c}\text { Swelling } \\
\text { Ratio* }^{*}\end{array}$ & $\begin{array}{c}\text { Time } \\
\text { (mins) }\end{array}$ & $\begin{array}{c}\text { Swelling } \\
\text { Ratio* }^{*}\end{array}$ \\
\hline 1.2 & 5 & $60.13 \pm 2.34$ & 65 & $20.46 \pm 1.74$ & 125 & $25.74 \pm 1.12$ & 185 & $30.38 \pm 0.81$ \\
& 10 & $86.87 \pm 2.45$ & 70 & $57.24 \pm 1.39$ & 130 & $55.60 \pm 1.32$ & 190 & $59.63 \pm 0.64$ \\
& 15 & $101.60 \pm 2.09$ & 75 & $85.90 \pm 1.48$ & 135 & $89.09 \pm 1.48$ & 195 & $90.73 \pm 0.88$ \\
& 20 & $106.63 \pm 2.16$ & 80 & $103.70 \pm 1.39$ & 140 & $102.54 \pm 1.43$ & 200 & $103.16 \pm 0.78$ \\
& 25 & $113.18 \pm 2.32$ & 85 & $114.82 \pm 1.87$ & 145 & $108.41 \pm 0.78$ & 205 & $108.15 \pm 0.86$ \\
& 30 & $115.28 \pm 2.53$ & 90 & $118.58 \pm 1.55$ & 150 & $112.03 \pm 0.56$ & 210 & $113.42 \pm 0.7$ \\
\hline 7.4 & 35 & $60.49 \pm 1.9$ & 95 & $51.38 \pm 1.09$ & 155 & $64.46 \pm 1.06$ & 215 & $70.26 \pm 1.17$ \\
& 40 & $19.65 \pm 2$ & 100 & $21.56 \pm 1.25$ & 160 & $21.21 \pm 1.47$ & 220 & $20.52 \pm 1.02$ \\
& 45 & $9.79 \pm 1.19$ & 105 & $13.06 \pm 0.55$ & 165 & $15.36 \pm 1.01$ & 225 & $16.34 \pm 0.73$ \\
& 50 & $8.42 \pm 0.63$ & 110 & $10.81 \pm 0.22$ & 170 & $11.07 \pm 0.82$ & 230 & $12.23 \pm 0.93$ \\
& 55 & $7.67 \pm 1.22$ & 115 & $8.51 \pm 0.56$ & 175 & $9.34 \pm 0.74$ & 235 & $9.10 \pm 0.50$ \\
& 60 & $6.26 \pm 0.96$ & 120 & $6.1 \pm 0.71$ & 180 & $7.34 \pm 1.01$ & 240 & $7.65 \pm 0.71$ \\
\hline
\end{tabular}

* Mean \pm SD, $n=3$

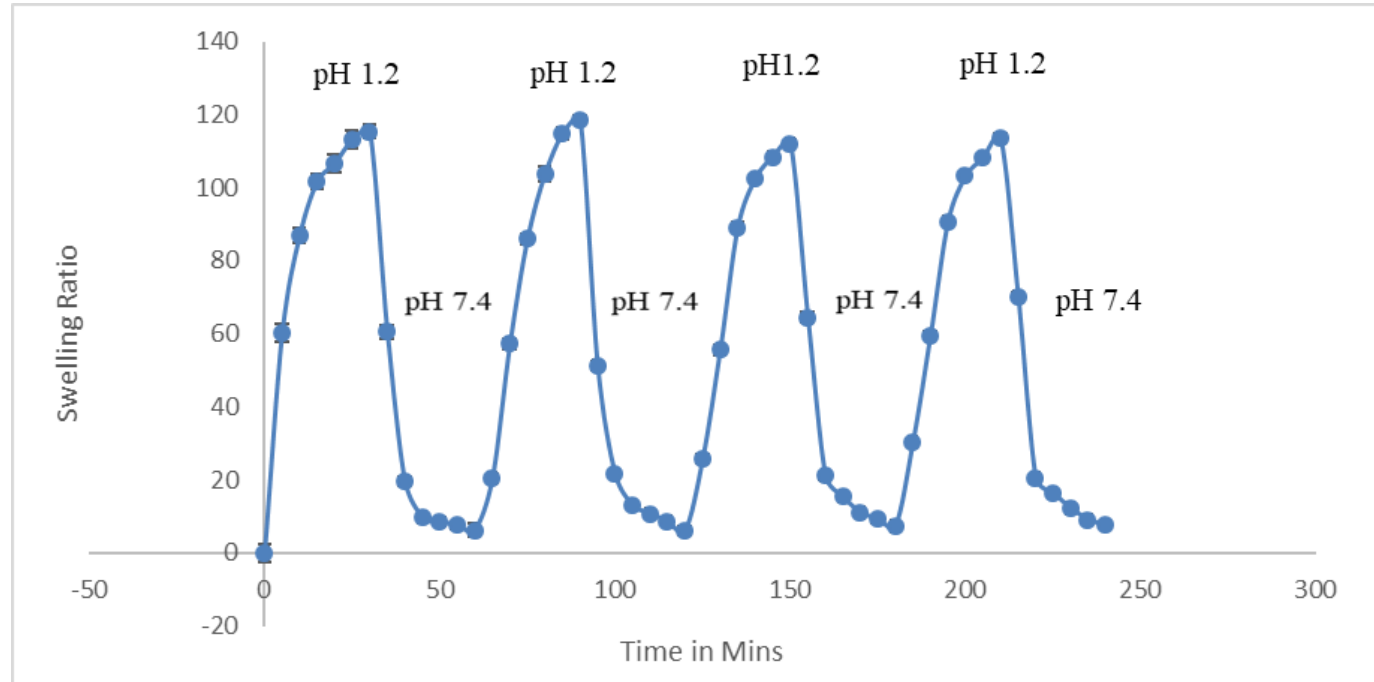

Figure 5. Swelling Reversibility profile of formulations F7.

\subsection{Determination of drug content}

Drug content of the considerable number of details was resolved and the outcomes got are appeared table 3. Structure the outcomes got, it was seen that the medication content in every one of the formulation ranges from $96.78-99.28 \%$, which shows tranquilize stacking just as dissemination is uniform over every one of the superporous hydrogels. 


\subsection{In vitro release studies}

In vitro release studies considers were done for every one of the details for $12 \mathrm{hrs}$ and the outcomes got are displayed in Table 5 and the drug release profile in Figure 6. Structure the outcomes it was seen that the greatest medication discharge was found in only F5, F6, F7 and F8. F1 and F2 formulations releases the drug in 8 hrs perios time that means it didnt tlease the drug continuosuly. In F 3 and F4 formulations it was observed that drug release ws upto 10hrs. In formulations F6, F7 and F8, the discharge was stretched out up to $12 \mathrm{~h}$. The drug release from the formulations was observed to be subject to the measure of crosslinking agent and polyvinyl Alcohol. Drug release was observed to be contrarily identified with the measure of crosslinking agent and at higher crosslink thickness where the openings are less discharge is additionally low.

Table 5. In vitro Drug Release Studies of vildagliptin loaded SPH Formulations.

\begin{tabular}{|c|c|c|c|c|c|c|c|c|}
\hline $\begin{array}{l}\text { Time } \\
\text { (Hrs) }\end{array}$ & F1 & F2 & F3 & F4 & F5 & F6 & F7 & F8 \\
\hline 0 & 0 & 0 & 0 & 0 & 0 & 0 & 0 & 0 \\
\hline 0.5 & $28.72 \pm 1.59$ & $22.67 \pm 2.42$ & $17.20 \pm 1.41$ & $20.48 \pm 1.82$ & $10.76 \pm 2.34$ & $8.44 \pm 1.51$ & $13.96 \pm 1.1$ & $16.6 \pm 1.02$ \\
\hline 1 & $46.08 \pm 1.13$ & $39.12 \pm 2.89$ & $23.36 \pm 1.68$ & $32.24 \pm 2.59$ & $15.04 \pm 1.78$ & $15.28 \pm 0.68$ & $18.52 \pm 2.8$ & $23.8 \pm 1.02$ \\
\hline 2 & $60.52 \pm 1.86$ & $59.08 \pm 2.77$ & $27.72 \pm 1.32$ & $45.56 \pm 2.41$ & $23.60 \pm 2.40$ & $28.40 \pm 1.52$ & $25.84 \pm 1.8$ & $\begin{array}{c}30.84 \pm \\
3.73\end{array}$ \\
\hline 3 & $75.04 \pm 1.56$ & $68.72 \pm 2.95$ & $35.32 \pm 1.82$ & $58.76 \pm 2.30$ & $35.44 \pm 2.35$ & $35.56 \pm 1.44$ & $\begin{array}{c}39.04 \pm \\
1.6\end{array}$ & $45.16 \pm 1.78$ \\
\hline 4 & $87.24 \pm 1.60$ & $75.00 \pm 2.53$ & $46.64 \pm 1.20$ & $69.72 \pm 1.87$ & $43.80 \pm 2.88$ & $43.24 \pm 0.68$ & $52.04 \pm 1.2$ & $50.68 \pm 1.44$ \\
\hline 6 & $98.68 \pm 0.24$ & $88.80 \pm 3.03$ & $69.04 \pm 1.47$ & $79.40 \pm 3.60$ & $53.64 \pm 1.74$ & $61.56 \pm 1.26$ & $61.72 \pm 1.4$ & $73.56 \pm 3.14$ \\
\hline 8 & $99.44 \pm 0.08$ & $97.76 \pm 1.68$ & $82.40 \pm 1.86$ & $90.80 \pm 0.85$ & $70.12 \pm 1.87$ & $72.44 \pm 0.78$ & $82.04 \pm 2.0$ & $84.52 \pm 2.38$ \\
\hline 10 & & & $97.72 \pm 1.74$ & $98.36 \pm 0.62$ & $91.52 \pm 2.71$ & $94.76 \pm 1.95$ & $95.04 \pm 1.2$ & $90.44 \pm 1.10$ \\
\hline 12 & & & & & $97.60 \pm 1.45$ & $98.56 \pm 1.00$ & $99.12 \pm 0.7$ & $97.24 \pm 1.36$ \\
\hline
\end{tabular}

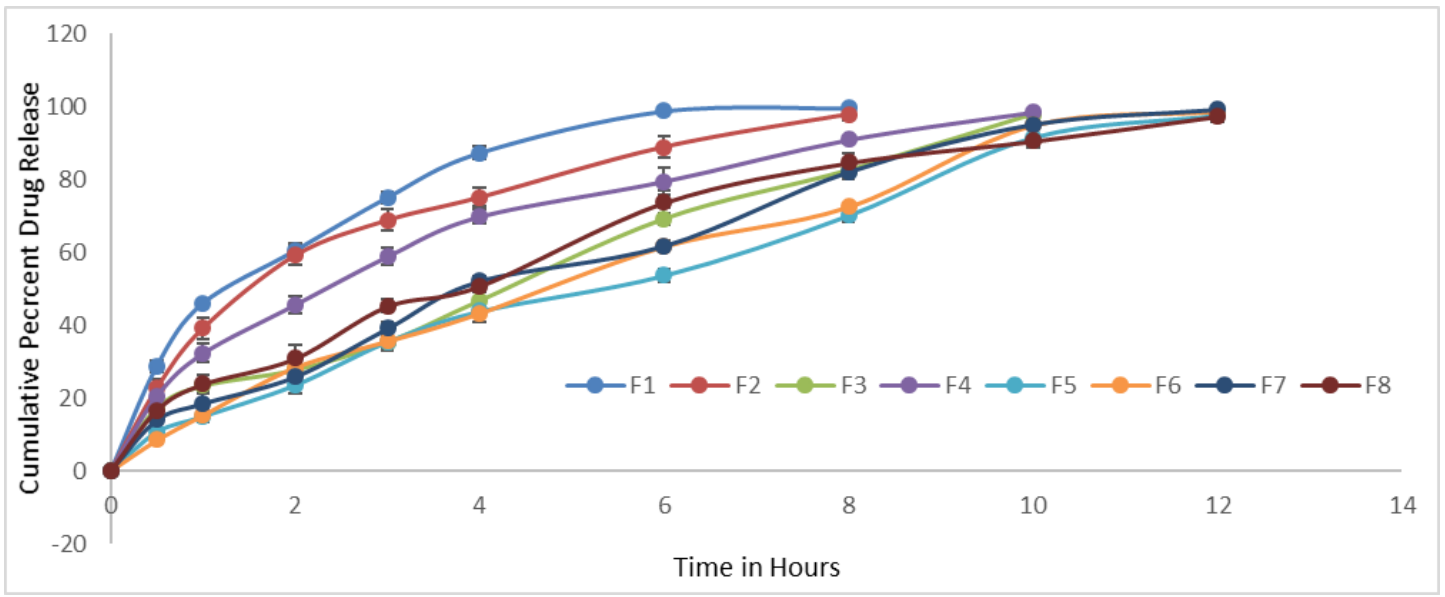

Figure 6. Cumulative Percent Drug Release of Formulations from F1 to F8.

\subsection{Drug release kinetics}

The in vitro drug release information of all formulations were exposed to numerical demonstrating. The estimations of $n$ and $R^{2}$ got were exhibited in Table 6 . The best fit model with the most astounding relationship coefficient esteems or assurance coefficient $\left(\mathrm{R}^{2}\right)$ for the definitions was observed to be zero request condition. F1, F2, F4 were found pursue first order release kinetics and F3,F5, F6, F8 follows zero order and higuchi release kinetics. At the point when these were fitted to Korsmeyer and Peppas condition, n esteems were $<0.89$ in every one of the cases, going from 0.456 to 0.774 . $n$ estimations of $<0.89$ shows that it pursues the Non Fickian discharge. The $\mathrm{R}^{2}$ estimations of zero order model for F3, F5, F6, F7 and F8 the formulations are essentially more prominent than that of first-order model showing the arrival of the medication is autonomous of fixation and the conveyance framework assumes a significant job in controlling the arrival of the medication. It was discovered that F7 formulation had great swelling proportion, better entanglement of medication stacking and studies of drug release. Accordingly F7 formulation was broke down for discharged active investigations. Therefore Kinetic investigations of F7 formulation by fitting them different numerical models, for example, zero order; first order; higuchi model; korsmeyer model and Hixon-Crowell. Regression $\left(\mathrm{R}^{2}\right)$ investigation of all plan were resolved and appeared in Figure 7. 
Table 6. $\mathrm{R}^{2}$ Values for different kinetic models for all formulations.

\begin{tabular}{|c|c|c|c|c|c|c|}
\hline & \multirow{2}{*}{$\begin{array}{c}\text { Zero } \\
\text { Order } \\
\left(\mathbf{R}^{2}\right) \\
\end{array}$} & \multirow{2}{*}{$\begin{array}{c}\text { First } \\
\text { Order } \\
\left(\mathbf{R}^{2}\right) \\
\end{array}$} & \multirow{2}{*}{$\begin{array}{c}\text { Hixon } \\
\text { Crowell } \\
\left(\mathbf{R}^{2}\right) \\
\end{array}$} & \multirow{2}{*}{$\begin{array}{c}\text { Higuchi } \\
\left(\mathbf{R}^{2}\right)\end{array}$} & \multicolumn{2}{|c|}{ Korsmeyer's- Peppas } \\
\hline & & & & & $\left(\mathbf{R}^{2}\right)$ & $\mathbf{n}$ \\
\hline F1 & 0.8075 & 0.9703 & 0.975 & 0.9694 & 0.9729 & 0.456 \\
\hline $\mathrm{F} 2$ & 0.8493 & 0.9623 & 0.984 & 0.94843 & 0.971 & 0.513 \\
\hline F3 & 0.979 & 0.7658 & 0.9194 & 0.959 & 0.9436 & 0.545 \\
\hline $\mathrm{F} 4$ & 0.8895 & 0.938 & 0.9881 & 0.9939 & 0.993 & 0.537 \\
\hline F5 & 0.986 & 0.8784 & 0.9543 & 0.9598 & 0.9912 & 0.69 \\
\hline F6 & 0.9807 & 0.877 & 0.958 & 0.9677 & 0.9961 & 0.774 \\
\hline F7 & 0.9689 & 0.887 & 0.9749 & 0.9746 & 0.977 & 0.653 \\
\hline F8 & 0.9431 & 0.916 & 0.9874 & 0.9866 & 0.9835 & 0.596 \\
\hline
\end{tabular}
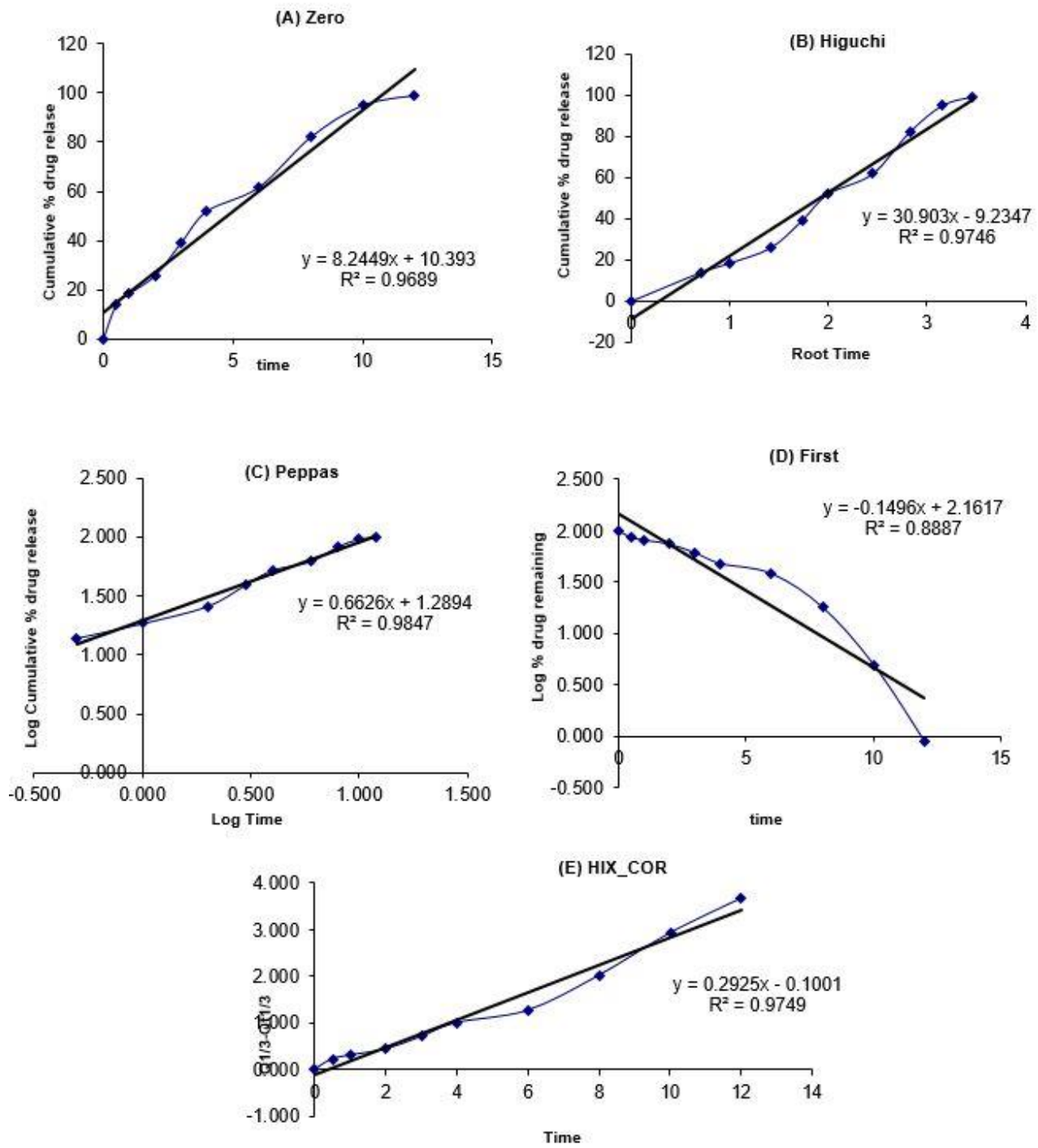

Figure 7. Release Kinetic profiles of Optimized formulation F7 (A) Zero Order (B) Higuchi (C) Peppa's (D) First Order (E) Hixon Crowell.

\subsection{FTIR studies}

The FTIR Spectra of pure drug vildagliptin displays tops at $1657.3 \mathrm{~cm}-1$ credits to $\mathrm{C}=\mathrm{O}$ extending, 3129.9 $\mathrm{cm}-1$ ascribes to carboxylic corrosive, $2915.5 \mathrm{~cm}-1$ is because of N-H twisting and $2237.6 \mathrm{~cm}-1$ demonstrates C-N extend. FTIR of enhanced detailing demonstrates tops at $3133.7 \mathrm{~cm}-1$ and $2915.4 \mathrm{~cm}-1$ uncovers the nearness of amide and the carboxylic gathering which affirmed the arrangement of polyacrylic corrosive co 
acrylamide superporous hydrogel. The FTIR think about uncovers that there is no extreme change in the assimilation pinnacles of vildagliptin in the last plan. This credits to the perception that there is negligible medication excipient and additionally contradiction. The outcomes were spoken to in Table 7 and appeared in Figure 8.

Table 7. FTIR Interpretation of Pure Drug and Optimized Formulation.

\begin{tabular}{cccc}
\hline S.No. & Functional Group & \multicolumn{2}{c}{ Observed Wave Number $\mathbf{( \mathbf { c m } ^ { - 1 } )}$} \\
& & Pure API & Optimized Formulation \\
\hline 1 & C=O (amide) & 1657.3 & 1657.9 \\
2 & O-H (Carboxylic Acid) & 3129.9 & 3133.7 \\
3 & N- H (amine) & 2915.5 & 2915.4 \\
4 & C - N (stretch) & 2237.6 & 2237.7 \\
\hline
\end{tabular}
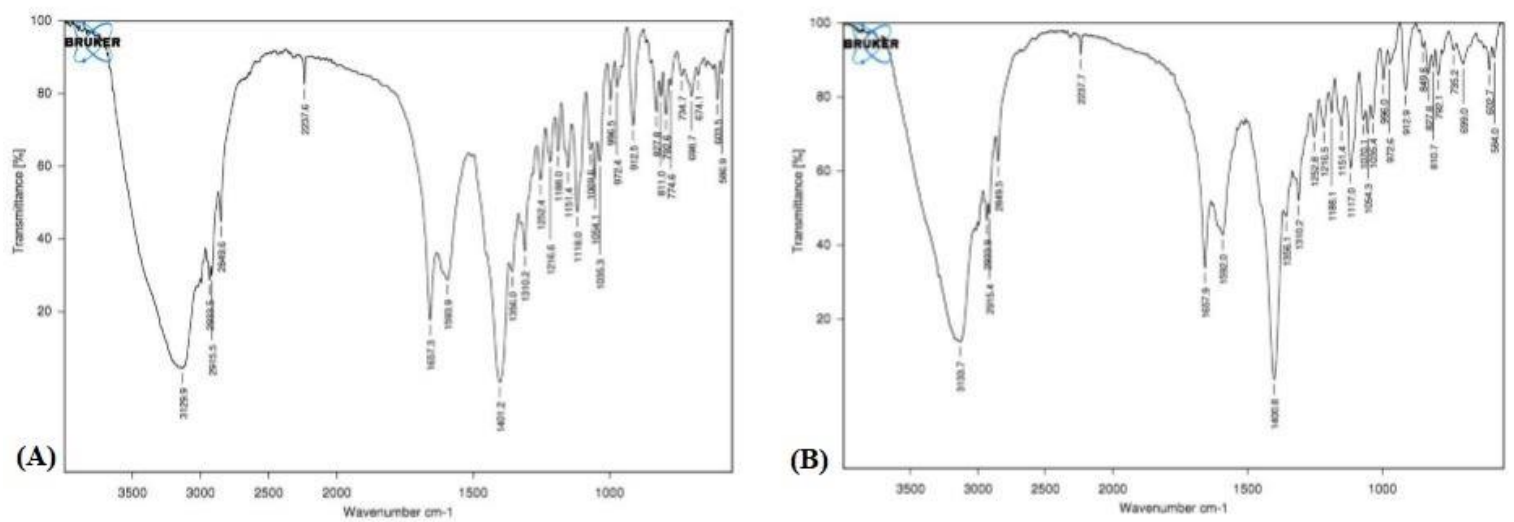

Figure 8. FTIR Spectra of (A) Pure Drug (B) Optimized Formulation.

\subsection{DSC studies}

DSC of pure drug Vildagliptin and drug stacked dried superporous hydrogel was demonstrated an endothermic top at $150.91^{\circ} \mathrm{C}$ and $154.81^{\circ} \mathrm{C}$ separately. The DSC of medication stacked superporous hydrogel demonstrated the equivalent endothermic pinnacle yet with expanding power showing that no cooperation of the medication with hydrogel polymeric system. The thermograms of both were appeared in Figure 9.

(A)

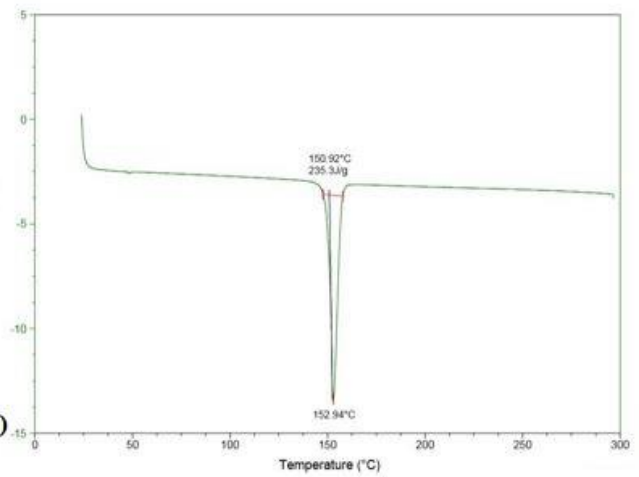

(B)

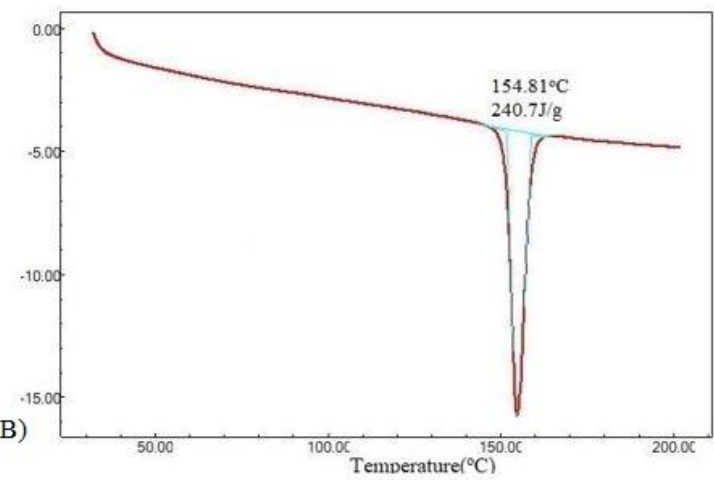

Figure 9. DSC studies of (A) Pure Drug (B) Optimized Formulation.

\subsection{SEM studies}

Scanning electron microscopy (SEM) was completed for the assurance of morphological portrayal of the superporous hydrogel. It was seen from Figure 10 that hydrogel had permeable structure which gives quicker swelling to the hydrogel. The profoundly permeable structure of hydrogel is in charge of better water entrance through the pores and that reason the successful medication discharge. 
(A)
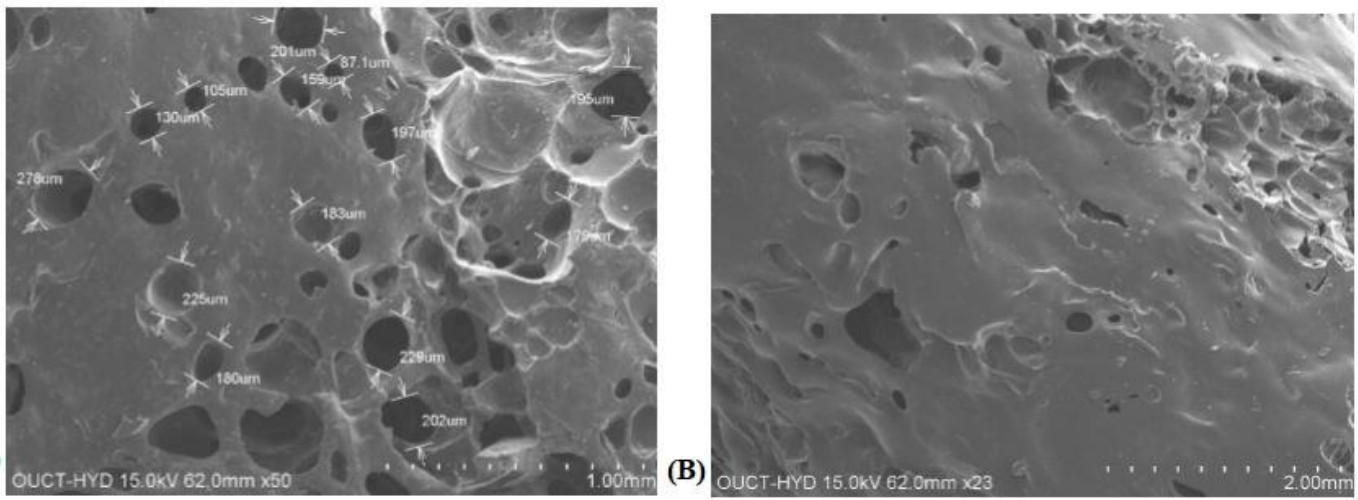

Figure 10. SEM Images of Optimized Formulations under magnification of (A)1.00mm (B) $2.00 \mathrm{~mm}$ showing porous surface.

\section{CONCLUSION}

The outcomes definitively exhibited that vildagliptin stacked superporous hydrogel was successfully arranged with wanted properties. The high polar interior surface of these pores inside the superporous hydrogels was in charge of the quick swelling rate which brought about a high swelling proportion of the superporous hydrogels. The medication discharge profile might be effectively identified with the swelling properties of these superporous hydrogels. From the investigation, it very well may be reasoned that the superporous hydrogels of vildagliptin arranged by gas blowing strategy utilizing BIS as a cross-connecting specialist and polyvinyl Alcohol as a composite operator have gastro retentive medication properties and can be utilized in the treatment of type II diabetes mellitus.

\section{MATERIAL AND METHODS}

\subsection{Materials}

Vildagliptin was obtained as a gift sample from Pharmatrain, Hyderabad. Polyvinyl Alcohol, Acrylic acid (AA), acrylamide (AM), N, N-methylene bisacrylamide (Bis), ammonium persulphate (APS), N, N, N', $\mathrm{N}^{\prime}$-tetramethylethylenediamine (TEMED) were procured from BMR Chemicals. Double distilled water (DDW) was prepared in the laboratory. All other chemicals used were of analytical grade and used as obtained.

\subsection{Preparation of plain superporous hydrogels $[12,13]$}

All ingredients aside from polyvinyl Alcohol and sodium bicarbonate were utilized as a solution in DDW. The $\mathrm{pH}$ of the monomer arrangements was acclimated to 5.5 with $5 \mathrm{M}$ sodium hydroxide arrangement. At the point when the $\mathrm{pH}$ monomer arrangement was lower than 5, carbon dioxide development occurred before the polymerization begins and no pores were shaped inside the incorporated SPHCs. For the amalgamation of superporous hydrogels the substances were included in this manner into a test tube at room temperature as appeared Table 8 . In this technique, polymerization was permitted to proceed for roughly 10 mins. In the wake of adding every substance to the test tube, the response blend was enthusiastically shaken. At last, sodium bicarbonate was added in all respects rapidly to the arrangement and blended with a spatula. In the event that sodium bicarbonate was not included rapidly enough, the polymerization had just been begun by ammonium persulphate as initiator, under this condition, a few cinches were shaped also and homogenous SPHC polymer was not acquired. After blend of SPHCs, they were expelled with the forceps, permitted to dry in the broiler at $60^{\circ} \mathrm{C}$ for $48 \mathrm{hrs}$, and cut into bits of the required size and put away in a sealed shut compartments to additionally utilize. 
Table 8. Composition of SPH formulations at various concentration of crosslinking agent.

\begin{tabular}{lcccccccc}
\hline Ingredients & F1 & F2 & F3 & F4 & F5 & F6 & F7 & F8 \\
\hline AM $(300 \mu 1)$ & $50 \% \mathrm{~W} / \mathrm{V}$ & $50 \% \mathrm{~W} / \mathrm{V}$ & $50 \% \mathrm{~W} / \mathrm{V}$ & $50 \% \mathrm{~W} / \mathrm{V}$ & $50 \% \mathrm{~W} / \mathrm{V}$ & $50 \% \mathrm{~W} / \mathrm{V}$ & $50 \% \mathrm{~W} / \mathrm{V}$ & $50 \% \mathrm{~W} / \mathrm{V}$ \\
$\mathrm{AA}(200 \mu \mathrm{1})$ & $50 \% \mathrm{~V} / \mathrm{V}$ & $50 \% \mathrm{~V} / \mathrm{V}$ & $50 \% \mathrm{~V} / \mathrm{V}$ & $50 \% \mathrm{~V} / \mathrm{V}$ & $50 \% \mathrm{~V} / \mathrm{V}$ & $50 \% \mathrm{~V} / \mathrm{V}$ & $50 \% \mathrm{~V} / \mathrm{V}$ & $50 \% \mathrm{~V} / \mathrm{V}$ \\
$\mathrm{BIS}(70 \mu \mathrm{l})$ & $0.5 \%$ & $0.5 \%$ & $0.5 \%$ & $1 \%$ & $1.5 \%$ & $2 \%$ & $2.5 \%$ & $3 \%$ \\
Span $80(30 \mu \mathrm{l})$ & $2.5 \% \mathrm{~V} / \mathrm{V}$ & $5 \% \mathrm{~V} / \mathrm{V}$ & $10 \% \mathrm{~V} / \mathrm{V}$ & $10 \% \mathrm{~V} / \mathrm{V}$ & $10 \% \mathrm{~V} / \mathrm{V}$ & $10 \% \mathrm{~V} / \mathrm{V}$ & $10 \% \mathrm{~V} / \mathrm{V}$ & $10 \% \mathrm{~V} / \mathrm{V}$ \\
APS $(25 \mu \mathrm{l})$ & $20 \% \mathrm{~W} / \mathrm{V}$ & $20 \% \mathrm{~W} / \mathrm{V}$ & $20 \% \mathrm{~W} / \mathrm{V}$ & $20 \% \mathrm{~W} / \mathrm{V}$ & $20 \% \mathrm{~W} / \mathrm{V}$ & $20 \% \mathrm{~W} / \mathrm{V}$ & $20 \% \mathrm{~W} / \mathrm{V}$ & $20 \% \mathrm{~W} / \mathrm{V}$ \\
TEMED $(25 \mu \mathrm{l})$ & $20 \% \mathrm{~W} / \mathrm{V}$ & $20 \% \mathrm{~W} / \mathrm{V}$ & $20 \% \mathrm{~W} / \mathrm{V}$ & $20 \% \mathrm{~W} / \mathrm{V}$ & $20 \% \mathrm{~W} / \mathrm{V}$ & $20 \% \mathrm{~W} / \mathrm{V}$ & $20 \% \mathrm{~W} / \mathrm{V}$ & $20 \% \mathrm{~W} / \mathrm{V}$ \\
PVA & $200 \mathrm{mg}$ & $200 \mathrm{mg}$ & $200 \mathrm{mg}$ & $200 \mathrm{mg}$ & $200 \mathrm{mg}$ & $200 \mathrm{mg}$ & $200 \mathrm{mg}$ & $200 \mathrm{mg}$ \\
Sodium & $100 \mathrm{mg}$ & $100 \mathrm{mg}$ & $100 \mathrm{mg}$ & $100 \mathrm{mg}$ & $100 \mathrm{mg}$ & $100 \mathrm{mg}$ & $100 \mathrm{mg}$ & $100 \mathrm{mg}$ \\
Bicarbonate & & & & & & & &
\end{tabular}

\subsection{Characterization of superporous hydrogels}

\subsubsection{Measurement of density [14]}

For density determination, solvent displacement method was used. Dried SPHC was used for density measurement, which actually showed the apparent density of SPHC. A piece of SPHC was taken and weighed in order to determine the mass of the piece. A piece of the polymer was immersed in a pre-determined volume of hexane in a graduated cylinder and the increase in hexane volume was measured as the volume of the polymer. The density was calculated by

Density $=\mathrm{M}_{\mathrm{SPHC}} / \mathrm{V}_{\mathrm{SPHC}}$

Where, $\mathrm{V}_{\mathrm{SPHC}}$ is the volume of the solvent displaced by SPHC and M $\mathrm{SPHC}$ is the mass of the SPHC.

\subsubsection{Measurement of porosity [15]}

The dried SPHC was submerged in hexane overnight and weighed after excess hexane on the surface was blotted. The porosity was calculated by

Porosity $=\mathrm{V}_{\mathrm{p}} / \mathrm{V}_{\mathrm{T}}$

Where, $\mathrm{V}_{\mathrm{p}}=\mathrm{V}_{\mathrm{T}}-\mathrm{V}_{\mathrm{SPHC}}$ is the pore volume of SPHC and $\mathrm{V}_{\mathrm{T}}$ is the total volume of SPHC. The total volume of SPHC can be measured from its dimensions as it is cylindrical in shape.

$\mathrm{V}_{\mathrm{T}}$ was calculated as $\mathrm{V}_{\mathrm{T}}=\pi \mathrm{r}^{2} \mathrm{~h}$.

\subsubsection{Determination of void fraction [16]}

The void fraction inside super porous hydrogels was determined by immersing the hydrogels in $\mathrm{HCl}$ solution ( $\mathrm{pH}$ 1.2) up to equilibrium swelling. By using this data, the dimensions of the swollen hydrogels, sample volumes were determined. The difference between the weight of the swollen hydrogel and the weight of dried hydrogel gives the amount of buffer absorbed into the hydrogels and it indicates the total volume of pores in the hydrogels.

The void fraction was calculated by the following equation (Eq. 3):

Void Fraction $=$ Dimensional volume of the hydrogel $/$ Total volume of pores

\subsubsection{Determination of swelling ratio [17]}

At the beginning of each experiment, the dried gel was measured gravimetrically to obtain $M_{d}$ and then it was immersed in excess of the medium for swelling. At various time intervals, the hydrogel was removed from the medium and weighed when excess hexane on the surface was blotted to determine Ms. Graph was plotted between swelling ratio vs time (min).

The equilibrium swelling ratio can be calculated as follows.

$\mathrm{Q}=\left(\mathrm{M}_{\mathrm{s}}-\mathrm{M}_{\mathrm{d}}\right) / \mathrm{M}_{\mathrm{d}}$

Where, $\mathrm{Q}$ is the equilibrium swelling ratio,

$M_{s}$ is the mass in the swollen state

$M_{d}$ is the mass in the dried state. 


\subsection{Drug loading [18]}

Vildagliptin was splashed up inside SPH by keeping emptied SPH into the medication arrangement in a decided volume of buffer. The decided volume of cradle identified with the amount of cushion required for complete swelling of SPH. At that point the totally swollen SPH stacked with the vildagliptin tranquilize was set in a broiler at $40^{\circ} \mathrm{C}$ for drying medium-term.

\subsection{Estimation of drug content}

Drug content in SPH was evaluated by utilizing numerous extraction strategy. For this, Vildagliptin stacked SPH was set in a measuring utencil containing $50 \mathrm{ml}$ of $\mathrm{HCl}$ support $\mathrm{pH} 1.2$ for extraction and blended for couple of minutes. Procedure was rehashed commonly until the whole medication was not separated . After that arrangement was gone through $0.45 \mu \mathrm{m}$ channel and medication substance was evaluated by UVVIS spectrophotometer at $230 \mathrm{~nm}$.

\subsection{In vitro release study [19]}

The in vitro release of vildagliptin from the prepared formulations were carried out using the USP type II dissolution apparatus, at a rotational speed of $100 \mathrm{rpm}$ in $900 \mathrm{ml} 0.1 \mathrm{~N} \mathrm{HCl}(\mathrm{pH} 1.2)$ at $37^{\circ} \mathrm{C} \pm 0.5^{\circ} \mathrm{C}$. Aliquots of $5 \mathrm{ml}$ sample were withdrawn at predetermined intervals and replenished with fresh dissolution medium to maintain a constant volume. The samples were filtered and analyzed spectrophotometrically at $230 \mathrm{~nm}$. All experiments were done in triplicate.

\subsection{Drug release kinetics}

Kinetic studies of drug release for selected SPH formulation was carried out with respect to different kinetic models viz; Zero order kinetics, first-order kinetics, Hixon and Crowell [20], Higuchi and Korsmeyer Peppas model [21]. After that regression analysis $\left(R^{2}\right)$ was determined and the diffusion coefficient $(n)$ was also calculated. The drug diffusion coefficient or release exponent (n) of the given controlled release formulation under study was calculated by comparing with the value of ' $n$ ' from the given Table 9 and drug release mechanism was determined.

Table 9. Reference table for drug release exponent (n) for the release mechanism.

\begin{tabular}{cc}
\hline Release Exponent (n) & Release Mechanism \\
\hline$<0.45$ & Fickian release (case I) \\
$0.45<\mathrm{n}<0.89$ & Non - Fickian release (Anomalous) \\
0.89 & Case - II transport \\
$>0.89$ & Super Case 0- II transport \\
\hline
\end{tabular}

\subsection{FTIR spectroscopy studies [22]}

The FTIR spectral measurements were taken at surrounding temperature utilizing a Bruker. Around 2 $\mathrm{mg}$ of the unrefined vildagliptin and medication stacked dried Superporous hydrogels were scattered in $\mathrm{KBr}$ powder and the pellets were made by applying $6000 \mathrm{~kg} / \mathrm{cm} 2$ weight. FTIR spectra were acquired by powder diffuse reflectance on FTIR spectrophotometer.

\subsection{Differential scanning calorimetry (DSC) [23]}

Thermal analysis of unadulterated vildagliptin and their SPH definition were performed utilizing thermal analyzer (Universal V4.5A TA instruments). Temperature pivot and cell steady were aligned by using indium (In). Precisely gauged medication $(2 \mathrm{mg}$ ) was exchanged to aluminum skillet and fixed. The example was warmed over a temperature scope of $30-350^{\circ} \mathrm{C}$, under dry nitrogen cleansing $(50 \mathrm{ml} / \mathrm{min})$ in pinhole aluminum dish.

\subsection{Scanning electron microscopy [24]}

The morphological investigations of SPH were completed by utilizing SEM. For this dried SPHs were sliced to uncover their inner structure. The examples were arranged independently on test holders. These holders were recolored with gold-palladium utilizing sputter coater for one moment under latent argon gas before electron magnifying lens examining. 
Acknowledgements: The authors wish to express gratitude toward Management and Principal of Vishnu Institute of Pharmaceutical Education and Research, Narsapur, Telangana, India for their profitable help and providing facilities for this research.

Author contributions: Concept - V.R., V.K.; Design - V.R., V.K.; Supervision - V.R., V.K.; Materials - P.K.D.; Data Collection and/or Processing - P.K.D.; Analysis and/or Interpretation - V.R., V.K.; Literature Search - P.K.D.; Writing - P.K.D., V.R.; Critical Reviews - V.R., V.K., P.K.D.

Conflict of interest statement: The authors declared no conflict of interest.

\section{REFERENCES}

[1] Ichikawa M, Kato T, Kawahara M, Watanabe S, Kayano M. A New Multiple-Unit Oral Floating Dosage System - InVivo Evaluation of Floating and Sustained-Release Characteristics with P-Amino Benzoic Acid and Isosorbide Dinitrate as Model Drugs. J Pharm Sci. 1991; 80(12): 1153-1156. [CrossRef]

[2] Leung SH, Trans BK, Robinson JR. Polyanionic Hydrogel as A Gastric Retention System. J Biomater Sci Polym Ed. 1993; 4(5): 483-492. [CrossRef]

[3] Stops F, Fell JT, Collett JH, Martini LG. Floating Dosage Forms to Prolong Gastro-RetentionThe Characterisation of Calcium Alginate Beads. Int J Pharm. 2008; 350(12): 301-311. [CrossRef]

[4] Praveen K S, Gayathri S A, Abhay A. Formulation development and Evaluation of Hydrogel Based Gastroretentive Drug Delivery System of AntiHypertensive Drug. In J Pharm Clin Res. 2016; 8(10): 1396-1401.

[5] Pratley RE, Afshin S, Glenn M. Review: Inhibition of dipeptidyl peptidase-4 with vildagliptin: a potential new treatment for type 2diabetes. Br J Diabetes Vasc Dis 2006; 6(4): 150-156.

[6] https://www.aace.com/files/dm-guidelines-ccp.pdf. (accessed December 9, 2018)

[7] Priyanka S, Shiva Kumar B, Ashraful Islam SM, Selim Raza Md, Santosh Adhikari. Design and Development of Immediate and Sustained Release tablets of Vildagliptin. Res J Pharm Biol Chem Sci. 2014; 5(4): 811-825.

[8] Vergnaud JM. Controlled drug release from oral dosage forms, Ellis Horwood Limited, London, 1993.

[9] Chien YW. Novel drug delivery systems, Second ed., Marcel Dekker, Inc., New York, 1992.

[10] Ahrén, B; Landin-Olsson, M, Jansson, PA, Svensson, M, Holmes, D, Schweizer, A. Inhibition of dipeptidyl peptidase-4 reduces glycemia, sustains insulin levels, and reduces glucagon levels in type 2 diabetes. J. Clin. Endocrinol. Metab. 2004; 89(5): 2078-84. [CrossRef]

[11] Mentlein, R; Gallwitz, B; Schmidt, WE. Dipeptidyl-peptidase IV hydrolyses gastric inhibitory polypeptide, glucagon-like peptide-1(7-36)amide, peptide histidine methionine and is responsible for their degradation in human serum. Eur. J. Biochem. 1993; 214(3): 829-35. [CrossRef]

[12] Manish Kumar Singh, Pramod Kumar Sharma, Nitin Sharma. Gastroretentive Drug Delivery System based On Natural Mucoadhesive Polymer. J Pharm Res. 2011; 4(2): 519-21.

[13] Desu PK, Rao PV and Kotra V. Synthesis and characterization of PVA based poly (acrylic acid-co-acrylamide) superporous hydrogels composites. Int J Pharm Sci Res. 2018; 9(10): 4361-67. [CrossRef]

[14] Dorkoosh FA, Brussee J, Verhoef JC, Borchard G, RafieeTehrani M, Junginger HE. Preparation and NMR characterization of superporous hydrogels and Superporous hydrogel composites. Polymer. 2000; 41(23): 8213-8220. [CrossRef]

[15] Kumar KA, Reddy MS, Manohara P, Babu PS. A review on gastro-retentive superporous hydrogels and its generations. Journal of Chemical and Pharmaceutical Sciences. 2012; 5(2): 78-81.

[16] Chavda HV, Patel CN, Karen HD. Preparation and characterization of chitosan-based superporous hydrogel composite. J Young Pharm. 2009; 1(3): 199-204.

[17] Bagadiya A, Kapadiya M, Mehta K. Superporous hydrogel: a promising tool for gastro retentive drug delivery system. In J pharm Tech. 2011;3(4): 1556-1571. [CrossRef]

[18] Pati NB, Velivela S, Mayasa V, Gupta VRM. Gastroretentive superporous hydrogel tablets of dexlansoprazole. Int J Pharm Sci Res 2016; 7(11): 4678-4685. [CrossRef]

[19] S. Dineshmohan, G. Roja, Y. Harika, R. Harika, V. R. M. Gupta. Effect of Hydrophilic and Hydrophobic Polymer Combinations in Vildagliptin Sustained Release Tablets: Fabrication and In Vitro Characterization. Asian J. Pharm 2015; 9(4): 298-306. 
[20] Hixon AW, Crowell JH. Dependence of reaction velocity upon surface and Agitation. Indus Eng Chem. 1931; 23(10): 923-31. [CrossRef]

[21] Korsmeyer RW, Gurny R, Doelker E. Mechanisms of solute release from porous hydrophilic polymers. Int J Pharm. 1983; 15(1): 25-35. [CrossRef]

[22] Gupta VN, Shiva Kumar GH. Investigation of swelling behaviour and mechanical properties of a $\mathrm{pH}$-sensitive superporous hydrogel composite. Iran J Pharm Res. 2012; 11(2): 481-493.

[23] Ray D, Sahoo PK, Mohanta GP. Designing of superporous cross-linked hydrogels containing acrylic-based polymer network. Asian J. Pharm. 2008; 2(2):123127.

[24] Santosh R. Tambe1, Leena P. Deore Devidas G. Bachhav. Formulation Development and Characterization of Superporous Hydrogel of Itopride Hydrochloride for Gastroretentive Drug Delivery System. W J Pharm Res. 2015; 4(2): 1552-1573.

This is an open access article which is publicly available on our journal's website under Institutional Repository at http://dspace.marmara.edu.tr. 